\title{
Nephrotic Syndrome in the Course of Treatment of Wilson's Disease with DL-Penicillamine
}

\author{
M. KARP,^ M. LURIE, and Z. YONIS† \\ From the Departments of Paediatrics and Pathology, Beilinson Hospital, Petah-Tikva, Israel
}

The nephrotic syndrome is a rare complication of the treatment of Wilson's disease with penicillamine. The case is presented of a young girl treated with DL-penicillamine for the hepatic type of Wilson's disease, who died of renal failure during treatment. A preliminary report of the case was published by Yonis and Karp (1963).

\section{Case Report}

At the age of 8 years, a girl, who was of Jewish-Yemenite origin, had transient jaundice which was diagnosed as infective hepatitis. During the following $1 \frac{1}{2}$ years she felt well, except for slight pain in the liver region. At the age of $9 \frac{1}{2}$ she was admitted for investigation, when a diagnosis of hepatic type of Wilson's disease was made. There was no jaundice. Neurological examination and EEG examination were normal. The liver was palpable $3 \mathrm{~cm}$. below the right costal margin. A Kayser-Fleischer ring was present. Kidney function tests were normal. There was no aminoaciduria. Liver flocculation tests were positive $1+$, SGOT 100-120 units. Retention of bromsulphalein was $46 \%$ in 5 minutes and $19 \%$ in 45 minutes. Caeruloplasmin in the serum was 0.05 oxidase activity optical units (normal for our laboratory, 0 1-0 3). Copper excretion in the urine $249 \mu \mathrm{g} . / 24 \mathrm{hr}$.; serum copper $50-86 \mu \mathrm{g} . / 100 \mathrm{ml}$.

The patient's younger sister was first examined in our department at the age of 7 ; she was found to have a low serum caeruloplasmin level, and high excretion of copper in the urine. There was no Kayser-Fleischer ring and the liver tests were almost normal. She is now undergoing further investigation. The parents and the other 5 children were all normal.

After the diagnosis of Wilson's disease had been confirmed, the patient was treated with $0.5 \mathrm{~g}$. DLpenicillamine per day. This treatment was given regularly for 3 months, during which time the copper excretion in the urine rose to an average of $700 \mu \mathrm{g} . / 24$ hours. During the following 10 months, she did not receive continuous treatment as she failed to consult her

\footnotetext{
Received March 7, 1966.

* Present address: The Rogoff and Wellcome Medical Research Institutes, Beilinson Hospital, Petah-Tikva, Israel.

† Dr. Z. Yonis died on April 27, 1965.
}

physician. At the end of that period, she was again examined, when no change was found in her clinical condition or in the biochemical findings. Urine contained no glucose, protein, bile pigments, or sediment. She was again given DL-penicillamine, $0.5 \mathrm{~g}$./day; the copper excretion in the urine was $250-1000 \mu \mathrm{g}$. $/ 24$ hours.

She was discharged from the hospital after one month of treatment, but was readmitted a few days later with convulsions and the sudden appearance of generalized oedema, and with anuria. Serum proteins were $3.5 \mathrm{~g}$./ $100 \mathrm{ml}$., with $0.8 \mathrm{~g} . / 100 \mathrm{ml}$. albumin; cholesterol $440 \mathrm{mg}$./ $100 \mathrm{ml}$., urea $110 \mathrm{mg} . / 100 \mathrm{ml}$. She was given intravenous albumin and $20 \%$ glucose solution, but did not secrete any urine. Within 24 hours the plasma urea rose to $207 \mathrm{mg}$. $/ 100 \mathrm{ml}$. and potassium to $7 \cdot 1 \mathrm{mEq} / 1$., followed by coma and convulsions. Peritoneal dialysis was unsuccessful and the patient died 36 hours after admission.

Necropsy. This had to be limited to the thoracic and abdominal organs.

The heart $(120 \mathrm{~g}$.) and lungs were normal. The liver (650 g.) had a fine granular appearance; it was of pale grey colour with firm consistency, the cut surface showing a nodular structure with wide grey bands separating the nodules. Gall-bladder and bile-duct were normal.

The spleen ( $250 \mathrm{~g}$.) was enlarged, moderately firm, of dark red colour.

The kidneys were considerably enlarged, combined weight $300 \mathrm{~g}$. (normal average $165 \mathrm{~g}$.). The outer surface was pale and smooth. The cut surface showed a widened pale grey-yellow cortex with clearly outlined medulla. Pelvis and calyces were normal.

Microscopical examination. The liver showed portal cirrhosis with marked proliferation of intralobular connective tissue (Fig. 1). Rubeanic acid staining for copper (Okamoto, Utamura, and Mikami, 1938) demonstrated tiny brown granules located within liver cells and dispersed in the connective tissue. None were found in Kupffer cells. Several granules were observed within the epithelium of the bile-ducts.

In the kidneys the most striking changes were in the tubules. Epithelial cells of primary convoluted tubules were swollen, resembling the findings in the so-called osmotic nephrosis. The most distinct changes were found in the distal convoluted tubules. In some areas 


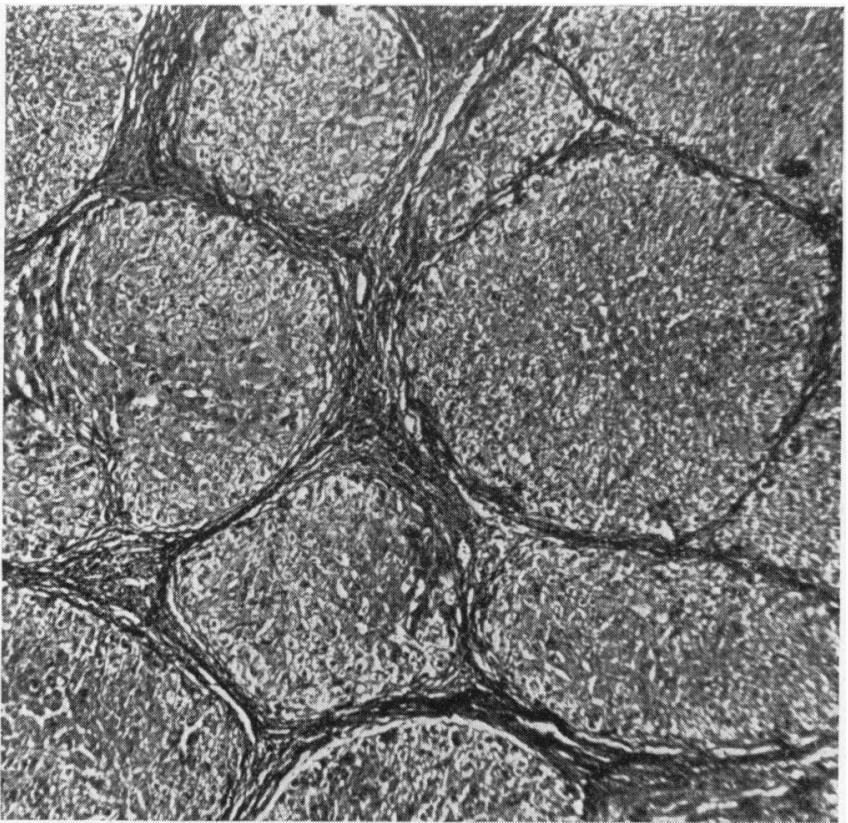

FIG. 1.-Liver, showing portal cirrhosis. (Haematoxylin and eosin. $\quad \times 55$.

there was necrosis and desquamation of tubular epithelium (Fig. 2 and 3). Necrotic conglomerated epithelial cells and hyaline casts were found within the lumen (Fig. 3). Some epithelial cells were calcified. Homo- geneous, birefringent crystals, about $20 \mu$ in diameter, with radial lines, were seen within the lumen of distal convoluted tubules. Some sudanophilic droplets were found in the epithelium of the proximal convoluted and collect-

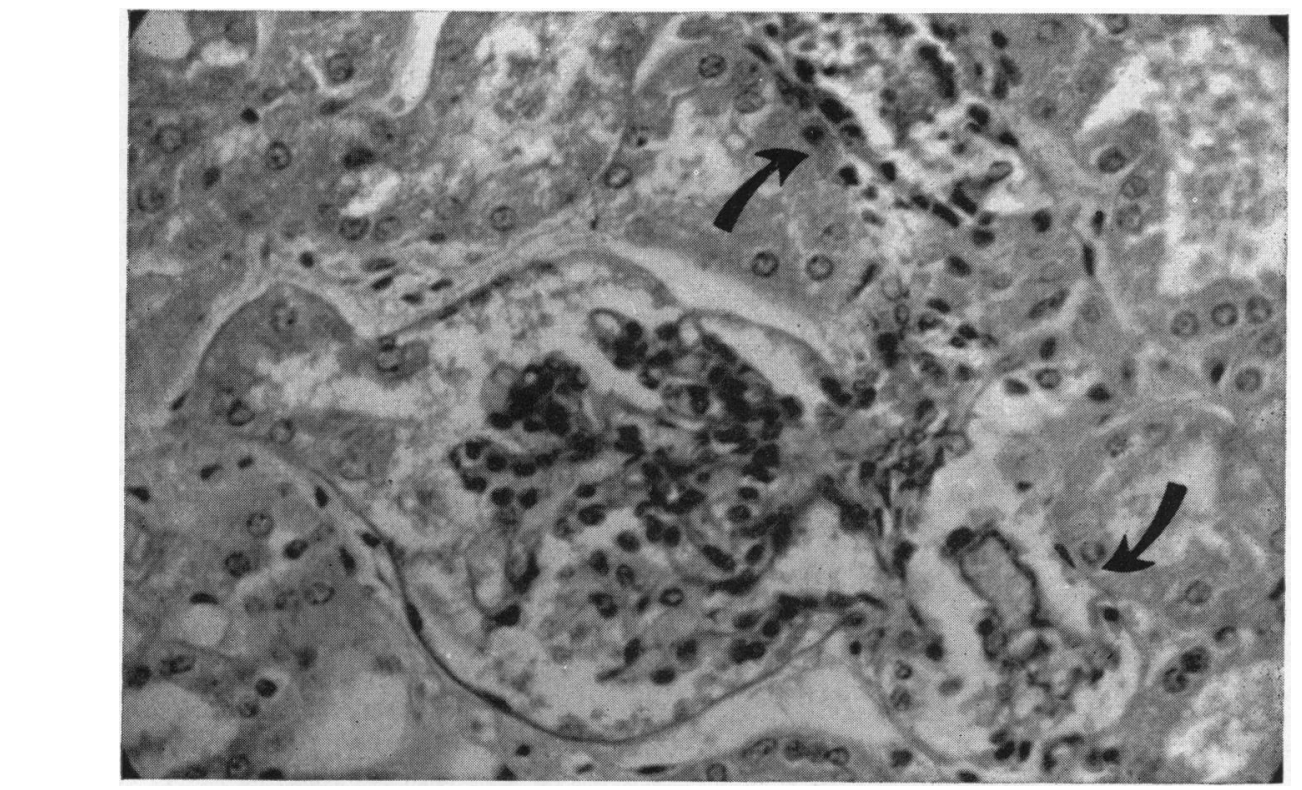

Fig. 2.-Kidney. Glomerulus and two distal convoluted tubules with necrotic epithelium (arrows). Note swelling of

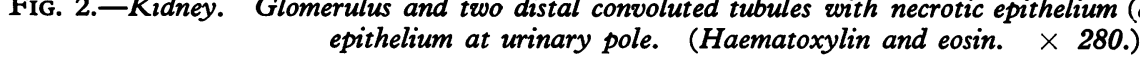



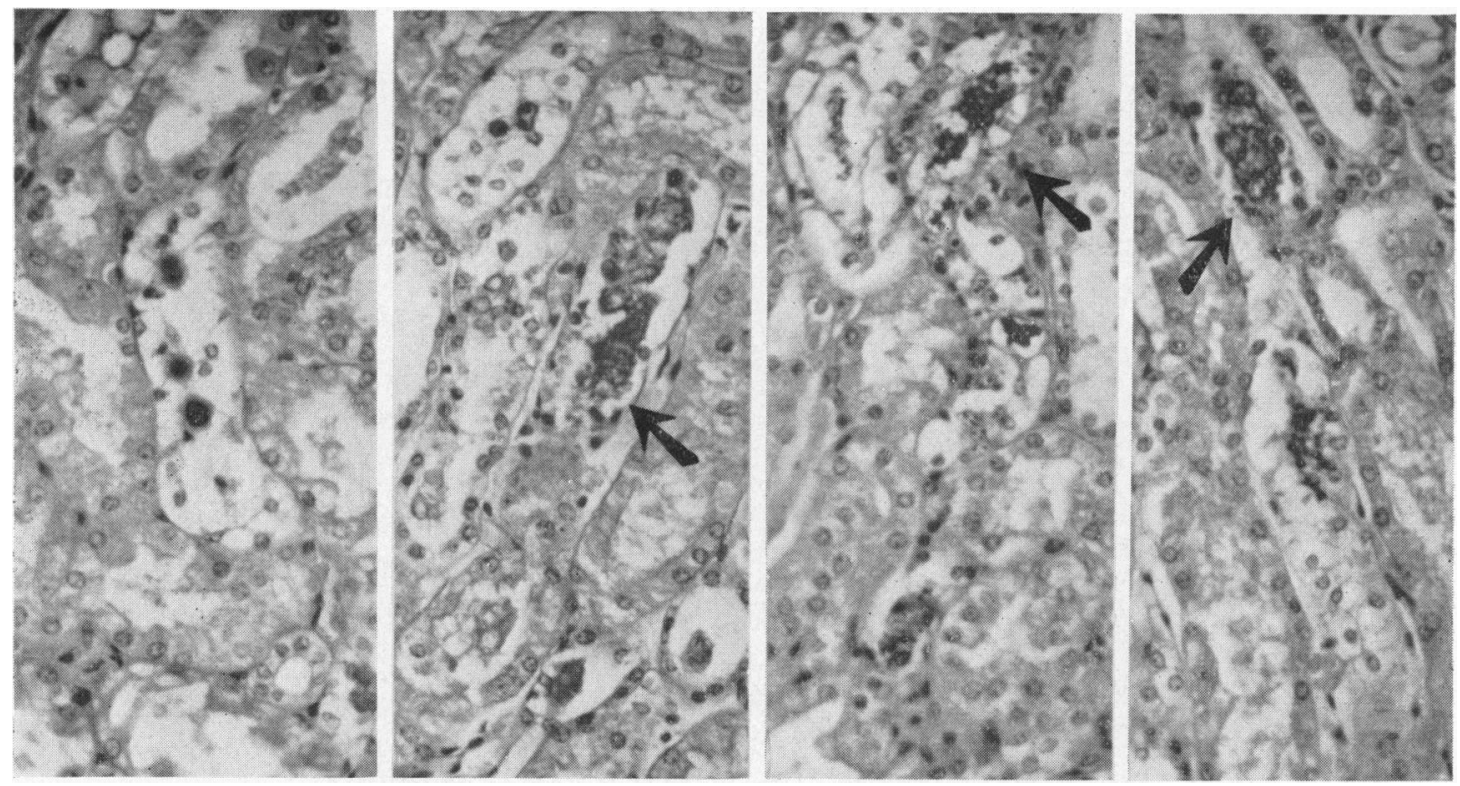

Fig. 3.-Kidney. Tubular necrosis in distal convoluted and collecting tubules. (Haematoxylin and eosin. $\times 150$.

ing tubules. The glomerular changes were less distinct: Bowman's spaces were sometimes wide, often showing a funnel-shaped urinary pole. Within Bowman's space an eosinophilic proteinous granular material was seen. A large number of Bowman's spaces appeared to be empty, probably partly due to the tangential section of the widened capsules. There was some shrinkage and apparently also disintegration of glomerular tufts. Sometimes the capsular epithelium and visceral epithelium were swollen. In some of the glomerular tufts the peripheral loops were indistinct and the basal membrane seemed to be broken, but there was no haemorrhage into Bowman's space. There was marked interstitial oedema, but nowhere was any kind of tissue reaction visible; no leucocytic or round cell infiltration was seen.

Rubeanic acid staining showed an abundance of granules located within the epithelial cells in both proximal and distal tubules. The impression was that the majority of the granules were located in the basal membrane of the tubules. Granules were also observed in the glomerular tufts and Bowman's capsule.

The lungs showed a peribronchial interstitial inflammatory infiltrate in addition to slight emphysema.

The heart showed lymphocytic and leucocytic infiltration at the epicardial surface. Small foci of infiltration were also seen in the myocardium.

Specimens of formalin-fixed liver and kidney tissue were sent to Dr. I. Sternlieb of the Albert Einstein College of Medicine, New York, for quantitative copper estimation. The amount of copper in the liver was $1221 \mu \mathrm{g}$./g. dry tissue (normal, up to 50). In the kidney the amount was $174 \mu \mathrm{g}$./g. dry tissue (normal, 10-16).

\section{Discussion}

The first report of nephrotic syndrome during the course of treatment with penicillamine was given by Fellers and Shahidi (1959), who did not state which isomer of penicillamine was used. The patient was 16 and developed the nephrotic syndrome after 9 months of treatment with $2 \mathrm{~g}$. daily. Remission appeared 14 days after the drug was discontinued. Adams, Goldman, Maxwell, and Latta (1964) reported a patient of 41 who developed the nephrotic syndrome after 8 months of penicillamine treatment at a dose of $2.5 \mathrm{~g}$. daily (the isomer of penicillamine was not stated). Sternlieb and Scheinberg (1964) reported 3 other cases with similar complications.

In only a few descriptions of cases of Wilson's disease has a histological examination of the kidneys been reported. Several renal biopsies taken from patients with Wilson's disease have shown no significant abnormalities (Gilsanz, Barrera, and Anaya, 1960; Playoust and Dale, 1961).

In 1964, however, Wolff described 5 cases of Wilson's disease in all of which the necropsy showed changes in the kidneys. The changes were confined to the tubules, and consisted of focal areas of degeneration, sloughing, and necrosis of tubular epithelial cells, findings that are more or less in accordance with those in our patient. The author considered the kidney changes to be due to the 'toxic' effect of copper deposits. Penicillamine therapy was not mentioned in this paper. 
Kark (1958) described one case in which renal biopsy showed that the changes were chiefly in the glomeruli. As in our case, there was widening of the intraglomerular space. There was also, however, an inflammatory infiltrate around the first loop of the proximal convoluted tubule, a finding that was not present in our case. Penicillamine therapy was not mentioned in this case either.

The experimental intraperitoneal injection of copper solution into mice (Vogel, 1960) or rats (Wolff, 1960) showed that copper might cause toxic kidney damage. In these experiments, degeneration and sloughing of epithelium were demonstrated in the proximal convoluted tubules in which copper granules had accumulated. In one experiment it was shown that copper passed through the glomerular filtrate before it accumulated in the proximal convoluted tubular epithelium.

There are few reports of cases of Wilson's disease which have been treated with penicillamine and which include a histological report of the kidneys, and these are absent in the case reports of Duckett, France, and Wallis (1962) and of Fellers and Shahidi (1959). Adams et al. (1964) give a detailed description of a kidney biopsy made on their patient with nephrotic syndrome after penicillamine therapy. Their essential finding was a glomerulitis in 2 out of 31 glomeruli contained in the biopsy specimen, with cellular proliferation involving epithelial and centrolobular cells. This is in contrast to the slight changes in the glomeruli in our case.

Penicillamine, first introduced by Walshe (1956), appears in two isomeric types, $D$ and $L$. In experimental animals the $\mathrm{L}$ isomer has proved to be toxic. Clinically, fever, rash, leucopenia, thrombocytopenia, and kidney damage have been noted with the DL isomer (Lancet, 1963). J. M. Walshe (1963, personal communications) suggested treating patients with the D-isomer only, and I. Sternlieb (1965, personal communications) claimed that sideeffects occurred with the DL isomer and not with the D isomer.

With regard to the functional kidney changes which frequently take place in Wilson's disease, it is not easy to decide whether the histological changes observed in our case were a sequel of the disease or of the penicillamine treatment. Our findings combined with those of others quoted, provide evidence pointing to copper accumulation as the cause of the tubular damage, but a toxic effect of penicillamine cannot be excluded. It should be stressed that the use of the $\mathrm{D}$-isomer of penicillamine is to be preferred.

\section{Summary}

A case is reported of a Jewish-Yemenite girl of 9 years, with the hepatic type of Wilson's disease, who died of nephrotic syndrome while being treated with DL-penicillamine. A description is given of the findings in the kidney, which consisted of severe tubular damage.

We are indebted to Professor J. Casper, head of the Institute of Pathology, Beilinson Hospital, who supervised the pathological studies and assisted in the preparation of this paper, to Professor I. Sternlieb for the quantitative copper estimation, and to Mrs. K. Norton for the photographic work.

\section{REFERENCES}

Adams, D. A., Goldman, R., Maxwell, M. H., and Latta, H. (1964). Nephrotic syndrome associated with penicillamine therapy of Wilson's disease. Amer. F. Med., 36, 330.

Duckett, S., France, N. E., and Wallis, P. G. (1962). Clinical and pathological findings in a case of hepatolenticular degeneration treated with penicillamine. F. Neurol. Neurosurg. Psychiat., 25, 374.

Fellers, F. X., and Shahidi, N. T. (1959). The nephrotic syndrome induced by penicillamine therapy. Amer. F. Dis. Child., 98, 669.

Gilsanz, V., Barrera, A., and Anaya, A. (1960). The renal biopsy in Wilson's disease. Arch. intern. Med., 105, 758.

Kark, R. M. (1958). Some aspects of nutrition and the kidney. Amer. F. Med., 25, 698.

Lancet (1963). Fresh light on myasthenia gravis. 2, 341.

Okamoto, K., Utamura, M., and Mikami, G. (1938). Acta Sch. med. Univ. Kioto, 22, 348. (Cited by Pearse, A. G. E., 1960. In Histochemistry, p. 940 . Churchill, London.)

Playoust, M. R., and Dale, N. E. (1961). Metabolic balance studies in a patient with Wilson's disease and hypercalcuria. Metabolism, 10, 304.

Sternlieb, I., and Scheinberg, I. H. (1964). Penicillamine therapy for hepatolenticular degeneration. F. Amer. med. Ass., 189, 748.

Vogel, F. S. (1960). Nephrotoxic properties of copper under experimental conditions in mice. Amer. F. Path., 36, 699.

Walshe, J. M. (1956). Wilson's disease, new oral therapy. Lancet, $1,25$.

Wolff, S. M. (1960). Copper deposition in the rat. Arch. Path., 69, 217.

- (1964). Renal lesions in Wilson's disease. Lancet, 1, 843.

Yonis, I. Z., and Karp, M. (1963). Chelating agents in Wilson's disease. ibid., 2, 689 .

\section{Addendum}

Since this paper was written, Reynolds, Tannen, and Tyler (1966) have published a paper describing the renal lesion.

REFERENCE

Reynolds, E. S., Tannen, R. L., and Tyler, H. R. (1966). The renal lesion in Wilson's disease. Amer. F. Med., 40, 518. 